OPEN ACCESS

Edited by: Gary W. Mack,

Brigham Young University,

United States

Reviewed by:

Filipe Dinato De Lima,

University Center of Brasilia, Brazil

Michael E. Tschakovsky,

Queen's University, Canada

${ }^{*}$ Correspondence:

Agnieszka Danuta Jastrzębska agnieszka.jastrzebska@awf.wroc.pl

Specialty section:

This article was submitted to

Exercise Physiology,

a section of the journal

Frontiers in Physiology

Received: 11 July 2021 Accepted: 07 October 2021

Published: 28 October 2021

Citation:

Hebisz P, Jastrzębska AD and Hebisz R (2021) Real Assessment

of Maximum Oxygen Uptake as a Verification After an Incremental Test

Versus Without a Test.

Front. Physiol. 12:739745. doi: 10.3389/fphys.2021.739745

\section{Real Assessment of Maximum Oxygen Uptake as a Verification After an Incremental Test Versus Without a Test}

\author{
Paulina Hebisz, Agnieszka Danuta Jastrzębska* and Rafał Hebisz \\ Department of Physiology and Biochemistry, University School of Physical Education in Wrocław, Wrockaw, Poland
}

The study was conducted to compare peak oxygen uptake $\left(\mathrm{VO}_{2 \text { peak }}\right)$ measured with the incremental graded test $(\mathrm{GXT})\left(\mathrm{VO}_{2 \text { peak }}\right)$ and two tests to verify maximum oxygen uptake, performed $15 \mathrm{~min}$ after the incremental test $\left(\mathrm{VO}_{2 \text { peak } 1}\right)$ and on a separate day $\left(\mathrm{VO}_{2 \text { peak2 }}\right)$. The aim was to determine which of the verification tests is more accurate and, more generally, to validate the $\mathrm{VO}_{2 \max }$ obtained in the incremental graded test on cycle ergometer. The study involved 23 participants with varying levels of physical activity. Analysis of variance showed no statistically significant differences for repeated measurements $\left(F=2.28, p=0.118, \eta^{2}=0.12\right.$ ). Bland-Altman analysis revealed a small bias of the $\mathrm{VO}_{2 \text { peak1 }}$ results compared to the $\mathrm{VO}_{2 \text { peak }}\left(0.4 \mathrm{ml} \cdot \mathrm{min}^{-1} \cdot \mathrm{kg}^{-1}\right)$ and $\mathrm{VO}_{2 \text { peak2 }}$ results compared to the $\mathrm{VO}_{2 \text { peak }}\left(-0.76 \mathrm{ml} \cdot \mathrm{min}^{-1} \cdot \mathrm{kg}^{-1}\right)$. In isolated cases, it was observed that $\mathrm{VO}_{2 \text { peak1 }}$ and $\mathrm{VO}_{2 \text { peak2 }}$ differed by more than $5 \%$ from $\mathrm{VO}_{2 \text { peak. }}$. Considering the above, it can be stated that among young people, there are no statistically significant differences between the values of $\mathrm{VO}_{2 \text { peak }}$ measured in the following tests. However, in individual cases, the need to verify the maximum oxygen uptake is stated, but performing a second verification test on a separate day has no additional benefit.

Keywords: maximum oxygen uptake, $\mathrm{VO}_{2}$ plateau, physical fitness, cycle ergometer, verification phase, incremental test

\section{INTRODUCTION}

Maximum oxygen uptake $\left(\mathrm{VO}_{2 \max }\right)$ is considered to be the gold standard in assessing oxygen capacity, as it reflects the efficiency of the respiratory and circulatory system and the efficiency of the muscular system in using oxygen whilst exercising (Bassett and Howley, 2000; Lucia et al., 2001; Martino et al., 2002; Joyner and Coyle, 2008). The incremental graded test (GXT) protocol is commonly used to assess the $\mathrm{VO}_{2 \max }$, which involves increasing the external load and continuing it until the subject reaches volitional exhaustion (Beltz et al., 2016). For years, the paradigm of the GXT was accepted and this form of $\mathrm{VO}_{2 \max }$ testing was used. However, for several years, there has been a discussion of whether the GXT in each case allows for an accurate measurement of maximum oxygen uptake (Howley et al., 1995; Poole et al., 2008; Sánchez-Otero et al., 2014; Schaun, 2017). It was pointed out that subjects with no experience for maximal efforts and those with low 
motivation and low cardiorespiratory fitness may interrupt the test before reaching $\mathrm{VO}_{2 \max }$ due to fatigue-related symptoms (Midgley et al., 2007b; Poole and Jones, 2017).

Therefore, new criteria for the accuracy of $\mathrm{VO}_{2 \max }$ measurements have been proposed (Howley et al., 1995; Sánchez-Otero et al., 2014; Beltz et al., 2016; Schaun, 2017). It has been suggested that achieving a $\mathrm{VO}_{2}$ plateau in the final phase of the GXT is proof that a $\mathrm{VO}_{2 \max }$ measurement is accurate (Howley et al., 1995). However, it has been documented that in many subjects (both athletes and non-athletes), it is impossible to separate the plateau phase when reaching $\mathrm{VO}_{2 \max }$ (Lucia et al., 2006; Schaun, 2017; Hebisz et al., 2018). The other criteria for accurately measuring $\mathrm{VO}_{2 \max }$-analysis of peak respiratory quotient, peak heart rate (HR), and post-workout lactate concentration-have also been widely discussed (Howley et al., 1995; Duncan et al., 1997; Beltz et al., 2016). Nonetheless, their high inter-subject variability may suggest that some subjects do not satisfy mentioned criterions even if their maximum effort is made, which lowers their value. It has been also demonstrated that the criterion of achieving a $\mathrm{VO}_{2}$ plateau in the final phase of the GXT frequently does not meet the criteria for $\mathrm{HR}$ and lactate concentration (Poole et al., 2008). These limitations reduce the certainty that subjects performing the GXT reach their "true" $\mathrm{VO}_{2 \max }$.

Considering the doubts about the effectiveness of the above-mentioned criteria in verifying the accuracy of $\mathrm{VO}_{2 \max }$ measurements, constant power verification tests were proposed (Midgley et al., 2006; Beltz et al., 2016; Poole and Jones, 2017; Schaun, 2017; Possamai et al., 2020). The idea is simply to provoke the $\mathrm{VO}_{2}$ plateau through constant-load effort performed with intensities ranging from submaximal to supramaximal effort (Barker et al., 2011; Nolan et al., 2014; Poole and Jones, 2017; Astorino and DeRevere, 2018). Usually, the verification tests are performed approximately 5-15 min after the incremental test (Schaun, 2017) and last several minutes (Barker et al., 2011; Nolan et al., 2014; Beltz et al., 2016; Schaun, 2017; Astorino and DeRevere, 2018).

On the other hand, Possamai et al. (2020) suggests that the test to verify the $\mathrm{VO}_{2 \max }$ obtained in the GXT should be performed on a different day, assuming that the subject's exercise tolerance/capacity is higher then and that the peak oxygen uptake $\left(\mathrm{VO}_{2 \text { peak }}\right)$ measured in a verification test on another day are not lower than that from a verification test performed several minutes after the GXT. However, in both verification tests they used a power output level of $100 \%$ of maximal power-as measured in a previous incremental test-which could have contributed to similar values of oxygen uptake being recorded in the tests. Moreover, their results showed that the $\mathrm{VO}_{2 \text { peak }}$ achieved in the verification test performed on a separate day were closer to the $\mathrm{VO}_{2 \text { peak }}$ of the GXT than that of a verification test done several minutes after the GXT.

More recently, in order to verify the $\mathrm{VO}_{2 \text { peak }}$ from the GXT, researchers proposed performing the verification test with a power level exceeding the power output of the GXT, but mainly several minutes after the GXT (Barker et al., 2011; Nolan et al., 2014; Schaun, 2017; Astorino and DeRevere, 2018). It seems that it would be worth using a higher load in the verification test performed on a separate day, as exercise tolerance is higher then.

The aim of this study was to compare the values of $\mathrm{VO}_{2 \text { peak }}$ obtained from the incremental test and from two verification tests completed with a power output of $110 \%$ of the peak power output reached in a previous incremental test [the first one was performed $15 \mathrm{~min}$ after the progressive test $\left(\mathrm{T}_{\mathrm{ver}-1}\right)$, whilst the second one was performed on a separate day $\left.\left(\mathrm{T}_{\mathrm{ver}-2}\right)\right]$. It was hypothesized that in individual cases, the verification test performed on a separate day may allow for higher $\mathrm{VO}_{2}$ peak values than the incremental test and the verification test performed several minutes after the incremental test.

\section{MATERIALS AND METHODS}

The study involved 23 participants: recreationally active individuals ( $n=13$, including 7 women and 6 men) and athletes (cyclists) ( $n=10$, including 4 women and 6 men). Each participant had been active recreationally or practicing sport (cyclists) for at least 3 years. The two groups, the recreationally active people and the athletes, were similar in regard to their anthropometric characteristics, whereas the parameters for physical capacity- $\mathrm{VO}_{2 \text { peak }}(p<0.000)$ and power value $\left(\mathrm{P}_{\max }\right)$ $(p<0.000)$ differed significantly (Table 1$)$.

The study design was approved by the institutional review board and was conducted in accordance with the ethical standards established by the Declaration of Helsinki. Written informed consent was obtained from all participants after the study details, procedures, benefits, and risks were explained.

\section{Exercise Tests}

The study consisted of three exercise tests (Figure 1). On the first day of the study, each participant performed an incremental graded test $(\mathrm{GXT})$ and a verification test $\left(\mathrm{T}_{\mathrm{ver}-1}\right)$. After a 48$\mathrm{h}$ break, an additional verification test $\left(\mathrm{T}_{\mathrm{ver}-2}\right)$ was performed, which was only preceded by a warm-up. The tests (GXT and $\mathrm{T}_{\mathrm{ver}-1}$ ) and $\mathrm{T}_{\mathrm{ver}-2}$ were performed at a similar time of day $( \pm 30 \mathrm{~min})$. All the tests were carried out using a Lode Excalibur Sport electronically braked cycloergometer (Lode BV, Groningen, Netherlands). The tests were performed in controlled laboratory conditions at an exercise laboratory (PN-EN ISO 9001:2001 certified). One week prior to the incremental graded test, the participants were familiarized with the protocol of the test.

\section{Incremental Exercise Test With Verification Test Performed on the Same Day}

The $\mathrm{VO}_{2 \text { peak }}$ was determined using a continuous GXT, with a self-selected pedal rate no lower than $60 \mathrm{rev} / \mathrm{min}$. The test started with a $40-\mathrm{W}$ or $50-\mathrm{W}$ load (for women and men, respectively), and it was increased by $40 \mathrm{~W}$ or $50 \mathrm{~W}$ (for women and men, respectively) every $3 \mathrm{~min}$ until volitional exhaustion. Heart rate was recorded with a V800 cardiofrequencimeter (Polar, Oy, Finland). The respiratory parameters were measured breath-bybreath (Quark, COSMED, Milan, Italy) and averaged over 30-s intervals. The data recording began 2 min before GXT and ended 
TABLE 1 | Basic anthropological and physiological parameters characterizing the subjects.

\begin{tabular}{|c|c|c|c|c|c|}
\hline & All $(n=23)$ & Recreational active $(n=13)$ & Athletes $(n=10)$ & Females $(n=11)$ & Males $(n=12)$ \\
\hline Age (years) & $22.00 \pm 3.79$ & $21.23 \pm 1.01$ & $23.00 \pm 5.64$ & $21.64 \pm 3.67$ & $22.33 \pm 4.03$ \\
\hline Body height (m) & $1.74 \pm 0.10$ & $1.76 \pm 0.11$ & $1.72 \pm 0.08$ & $1.67 \pm 0.06$ & $1.82 \pm 0.07^{\star}$ \\
\hline Body mass (kg) & $68.50 \pm 9.96$ & $70.64 \pm 11.38$ & $65.73 \pm 7.39$ & $61.75 \pm 6.92$ & $74.69 \pm 8.22^{\star}$ \\
\hline $\mathrm{VO}_{2 \text { peak } 1}\left(\mathrm{ml} \cdot \mathrm{kg}^{-1} \cdot \mathrm{min}^{-1}\right)$ & $52.00 \pm 13.31$ & $42.62 \pm 6.10$ & $64.18 \pm 9.58^{\star}$ & $45.46 \pm 8.44$ & $57.98 \pm 14.42^{*}$ \\
\hline $\operatorname{Pmax}(\mathrm{W})$ & $288.91 \pm 77.71$ & $244.23 \pm 56.26$ & $347.00 \pm 62.51^{*}$ & $230.64 \pm 49.31$ & $342.33 \pm 57.94^{*}$ \\
\hline
\end{tabular}

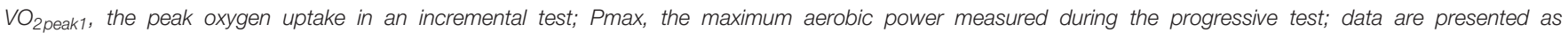
mean \pm standard deviation.

${ }^{*} p<0.05$ for the difference between groups.

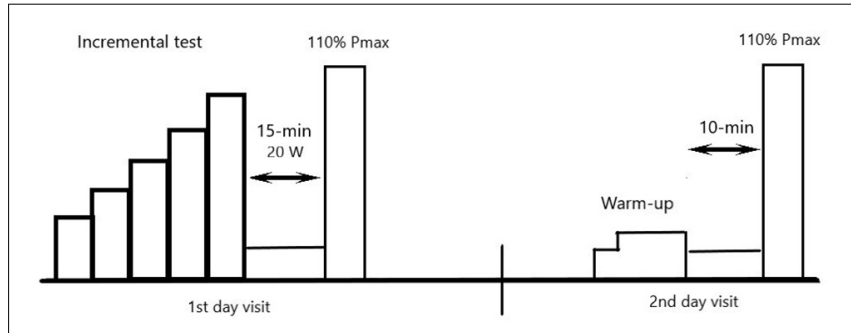

FIGURE 1 | Scheme of visit in laboratory.

5 min after the verification test $\left(\mathrm{T}_{\mathrm{ver}-1}\right)$. The device was calibrated with an atmospheric air and gas mixture: $5 \% \mathrm{CO}_{2}, 16 \% \mathrm{O}_{2}$, and $79 \% \mathrm{~N}_{2}$. Oxygen uptake $\left(\mathrm{VO}_{2}\right)$, exhaled carbon dioxide $\left(\mathrm{VCO}_{2}\right)$, and minute pulmonary ventilation (VE) were measured. The highest $\mathrm{VO}_{2}$ recorded in the GXT was taken as the $\mathrm{VO}_{2}$ peak, whilst the highest $\mathrm{VO}_{2}$ recorded in the $\mathrm{T}_{\mathrm{ver}-1}$ was taken as the $\mathrm{VO}_{2 \text { peak } 1 \text {. }}$

Based on the respiratory data records from the GXT, the first ventilatory threshold (VT1) was determined at the point preceding the first non-linear increase in $\mathrm{VE} \cdot \mathrm{VO}_{2}{ }^{-1}$ without a concomitant increase in $\mathrm{VE} \cdot \mathrm{VCO}_{2}{ }^{-1}$ equivalent; the second ventilatory threshold (VT2) was at the point preceding the second non-linear increase in $\mathrm{VE} \cdot \mathrm{VO}_{2}{ }^{-1}$ accompanied by an increase of $\mathrm{VE} \cdot \mathrm{VCO}_{2}{ }^{-1}$ equivalent, according to the methodology described by Davis et al. (1980) and Beaver et al. (1986).

The cycloergometer was controlled by a computer, which recorded instantaneous power and exercise time. The maximum aerobic $\mathrm{P}_{\max }$ was obtained by subtracting $0.22 \mathrm{~W}$ for women and $0.28 \mathrm{~W}$ for men for each missing second of the last performed load. After the end of the test, the subject rested for $15 \mathrm{~min}$, with an active rest on a $20-\mathrm{W}$ cycloergometer. Next, a 3-min, squarewave $\mathrm{T}_{\text {ver-1 }}$ was performed with an intensity of $110 \%$ of $\mathrm{P}_{\max }$ with regards to Schaun (2017).

\section{Verification Test Performed on a Different Day}

The test was preceded by a 15-min warm-up consisting of $5 \mathrm{~min}$ of exercise at an intensity corresponding to the power achieved with the VT1, then $10 \mathrm{~min}$ at a power corresponding to half the distance between the VT1 and the VT2. The warm-up was followed by a 10-min passive break. $\mathrm{T}_{\mathrm{ver}-2}$ was 3 min long and was performed at an intensity of $110 \%$ of $\mathrm{P}_{\max }$, as determined by the results of the incremental graded test performed 2 days prior. The recording of respiratory parameters started $1 \mathrm{~min}$ before the verification test and ended 5 min after it was completed. The values averaged every $30 \mathrm{~s}$ were used in data analysis. The highest recorded oxygen uptake (from the averaging of 30-s intervals) was taken as the $\mathrm{VO}_{2 \text { peak }}$ in the verification test performed on

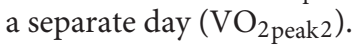

\section{Statistical Analysis}

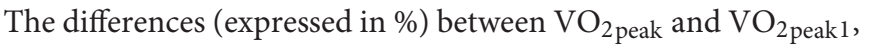
as well as between $\mathrm{VO}_{2 \text { peak }}$ were calculated for each participant. The tolerance of measurement error was at 5\% (Midgley et al., 2007a; Romero-Fallas et al., 2012; Hall-Lopez et al., 2015). Data normality was assessed through the Kolmogorov-Smirnov test with Lilliefors significance correction. Bland-Altman analysis was performed to determine the size of the difference shift between $\mathrm{VO}_{2 \text { peak }}$ and $\mathrm{VO}_{2 \text { peak1 }}$, as well as between $\mathrm{VO}_{2 \text { peak }}$ and $\mathrm{VO}_{2 \text { peak2 }}$. Pearson's correlation and linear regression were performed for comparing the results of GXT and $\mathrm{T}_{\mathrm{ver}-1}$ or $\mathrm{T}_{\text {ver-2. }}$ STATISTICA 13.1 software (StatSoft Inc., Tulsa, OK, United States) was used for further statistical processing of the data. All data are reported as mean \pm SD. Analysis of variance with repeated measurements and the Scheffe post hoc test were used to determine whether factors such as sex, athletic ability, or subsequent tests affected $\mathrm{VO}_{2 \text { peak }}$. The results were considered statistically significant at an alpha level of $p<0.05$.

\section{RESULTS}

The GXT and $\mathrm{T}_{\text {ver- } 2}$ were performed by 23 participants, while $\mathrm{T}_{\text {ver-1 }}$ was performed by 21 participants ( 2 participants refused to perform this test because of perceived fatigue).

The analysis of the main effects showed statistically significant differences in oxygen uptake for sex $(F=25.02 ; p=0.000$; $\left.\eta^{2}=0.60\right)$ and physical activity level $(F=74.24 ; p=0.000$; $\left.\eta^{2}=0.81\right)$. There were no statistically significant differences for repeated measurements $\left(F=2.28, p=0.118, \eta^{2}=0.12\right)$ or mixed effects for repeated measurements and $\operatorname{sex}(F=0.68, p=0.516$, $\left.\eta^{2}=0.04\right)$, nor for mixed effects for repeated measurements and physical activity level $\left(F=0.20, p=0.820, \eta^{2}=0.01\right)$ (Table 2$)$.

The individual analysis showed that 2 subjects in the $\mathrm{T}_{\mathrm{ver}-1}$ and 7 subjects in the $\mathrm{T}_{\text {ver-2 }}$ had a higher $\mathrm{VO}_{2 \text { peak }}$ by $5 \%$ than in the GXT (Table 3). Bland-Altman analysis (Figure 2) revealed

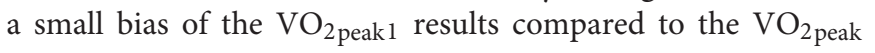


TABLE 2 | Peak oxygen uptake value in the incremental test and in the verification tests in the entire group of subjects, as well as after dividing the group according to sex and physical activity level.

\begin{tabular}{|c|c|c|c|}
\hline & \multicolumn{3}{|c|}{ Peak oxygen uptake $\left(\mathrm{VO}_{2}\right.$ peak) $\left[\mathrm{ml} \cdot \mathrm{min}^{-1} \cdot \mathrm{kg}^{-1}\right]$} \\
\hline & Progressive test $(n=23)$ & Verification test $1(n=21)$ & Verification test $2(n=23)$ \\
\hline Whole group $\left(n=23^{n}\right)$ & $51.99 \pm 13.31$ & $51.03 \pm 13.73$ & $52.75 \pm 13.37$ \\
\hline Females $(n=11)$ & $45.46 \pm 8.44$ & $44.09 \pm 7.79$ & $45.08 \pm 7.67$ \\
\hline Males $(n=12)$ & $57.98 \pm 14.42$ & $57.35 \pm 15.19$ & $59.78 \pm 13.85$ \\
\hline Athletes $\left(n=10^{\circ}\right)$ & $64.18 \pm 9.58$ & $64.94 \pm 10.30$ & $64.52 \pm 10.58$ \\
\hline Recreationally active $(n=13)$ & $42.62 \pm 6.10$ & $42.48 \pm 6.66$ & $43.70 \pm 6.32$ \\
\hline
\end{tabular}

Data are presented as mean \pm standard deviation.

$\wedge-21$ participants completed the verification test 1 , two athletes (one woman and one man) refused to participate in this test.

TABLE 3 | The number of people who achieved a lower, higher or equal peak oxygen uptake in the verification tests compared to the peak oxygen uptake achieved in the progressive test.

\begin{tabular}{|c|c|c|c|c|c|}
\hline & \multirow{2}{*}{$\frac{\text { Whole }}{\text { aroup }(n=23)}$} & \multicolumn{2}{|c|}{ I division } & \multicolumn{2}{|c|}{ Il division } \\
\hline & & Females $(n=11)$ & Males $(n=12)$ & Athletes $(n=10)$ & Recreationally active $(n=13)$ \\
\hline $\mathrm{VO}_{2 \text { peak }}<\mathrm{VO}_{2 \text { peak } 1}$ & 2 & 1 & 1 & 0 & 2 \\
\hline $\mathrm{VO}_{2 \text { peak }}>\mathrm{VO}_{2 \text { peak } 1}$ & 4 & 2 & 2 & 2 & 2 \\
\hline $\mathrm{VO}_{2 \text { peak }}=\mathrm{VO}_{2 \text { peak } 1}$ & 15 & 7 & 8 & 6 & 9 \\
\hline $\mathrm{VO}_{2 \text { peak }}<\mathrm{VO}_{2 \text { peak2 }}$ & 7 & 2 & 5 & 2 & 5 \\
\hline $\mathrm{VO}_{2 \text { peak }}>\mathrm{VO}_{2 \text { peak } 2}$ & 3 & 2 & 1 & 2 & 1 \\
\hline $\mathrm{VO}_{2 \text { peak }}=\mathrm{VO}_{2 \text { peak } 2}$ & 13 & 7 & 6 & 6 & 7 \\
\hline
\end{tabular}

The analysis was performed taking into account the division of the study group according to sex (I) and physical activity level (II).

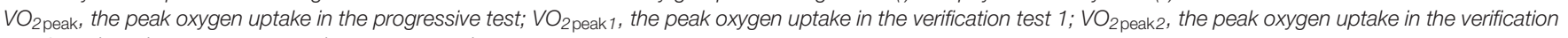
test 2 ; <, less than...; >, greater than...; =, equal....

$\left(0.4 \mathrm{ml} \cdot \mathrm{min}^{-1} \cdot \mathrm{kg}^{-1}\right)$ and $\mathrm{VO}_{2 \text { peak2 }}$ results compared to the $\mathrm{VO}_{2 \text { peak }}\left(-0.76 \mathrm{ml} \cdot \mathrm{min}^{-1} \cdot \mathrm{kg}^{-1}\right)$.

The raw test records that were performed in the studies described in this work are posted in the repository at https://repod.icm.edu.pl/dataset.xhtml?persistentId=doi: 10.18150/HGE2PK.

\section{DISCUSSION}

In order to assess the $\mathrm{VO}_{2 \text { peak, }}$, researchers traditionally use the GXT test until exhaustion. Since the primary criterion of $\mathrm{VO}_{2 \text { peak }}$ attainment-a $\mathrm{VO}_{2}$ plateau in exhaustion-is not always reached during the GXT, some researchers have postulated using subsequent verification tests (Niemelä et al., 1980; Midgley et al., 2007b; Poole and Jones, 2017). However, in the available literature, there are contradictory suggestions as to the need for verification tests. There are opinions that question the validity of performing tests to verify the $\mathrm{VO}_{2 \max }$ obtained from a progressive test, due to the minimal individual differences between the results of progressive and verifying tests (Rossiter et al., 2006; Murias et al., 2018; Brito et al., 2019). Similar results, confirmed by Bland-Altman analysis, were presented by McGawley (2017) when he compared the $\mathrm{VO}_{2 \text { peak }}$ measured in the progressive test with the $\mathrm{VO}_{2 \text { peak }}$ measured in a 4-min time trial run, performed on a separate day. The data presented herein show no differences in mean $\mathrm{VO}_{2}$ peak in the GXT and $\mathrm{T}_{\text {ver-1 }}$ versus $\mathrm{T}_{\text {ver-2 }}$ (Table 2 ). Bland-Altman analysis showed

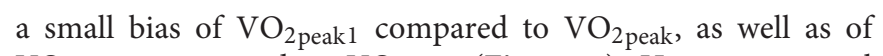
$\mathrm{VO}_{2 \text { peak2 }}$ compared to $\mathrm{VO}_{2 \text { peak }}$ (Figure 2). However, several subjects (both recreationally active people and athletes) achieved higher $\mathrm{VO}_{2 \text { peak } 1}$ or $\mathrm{VO}_{2 \text { peak2 }}$ values than $\mathrm{VO}_{2 \text { peak }}$. Therefore, we support the postulate of Poole and Jones (2017) about the need to perform tests verifying the values of $\mathrm{VO}_{2 \text { peak }}$ measured in progressive tests.

In most available literature, $\mathrm{VO}_{2 \max }$ verifier tests are performed on the same day as the progressive test (Midgley et al., 2007b; Astorino, 2009; Kirkeberg et al., 2011; Dalleck et al., 2012; Poole and Jones, 2017; Adam et al., 2018). The factor differentiating used procedures is the time between the tests. Intervals of between 5 and 15 min have commonly been used (Midgley et al., 2007b; Poole and Jones, 2017; Adam et al., 2018), although intervals ranging from 1 to 3 min (Kirkeberg et al., 2011) to even 60-90 min (Astorino, 2009; Dalleck et al., 2012; Nolan et al., 2014) have been used for verification tests performed on the same day. Nolan et al. (2014) reported no differences in $\mathrm{VO}_{2 \text { peak }}$ between verification tests performed with $105 \% \mathrm{P}_{\max }$ after 20 - and 60-min recovery periods. Thus, $20 \mathrm{~min}$ of recovery may be sufficient for physically active subjects. As noted by Scharhag-Rosenberger et al. (2011), comparable $\mathrm{VO}_{2 \text { peak }}$ values after an incremental test and verification test followed by a 10-min break indicates that even shorter breaks can be used. The results reported by Kirkeberg et al. (2011) show that even short recovery periods of 1-3 min turned out to be sufficient among physically active people. Regardless of the intervals used between the tests, it seems that the effectiveness of the $\mathrm{VO}_{2 \max }$ 

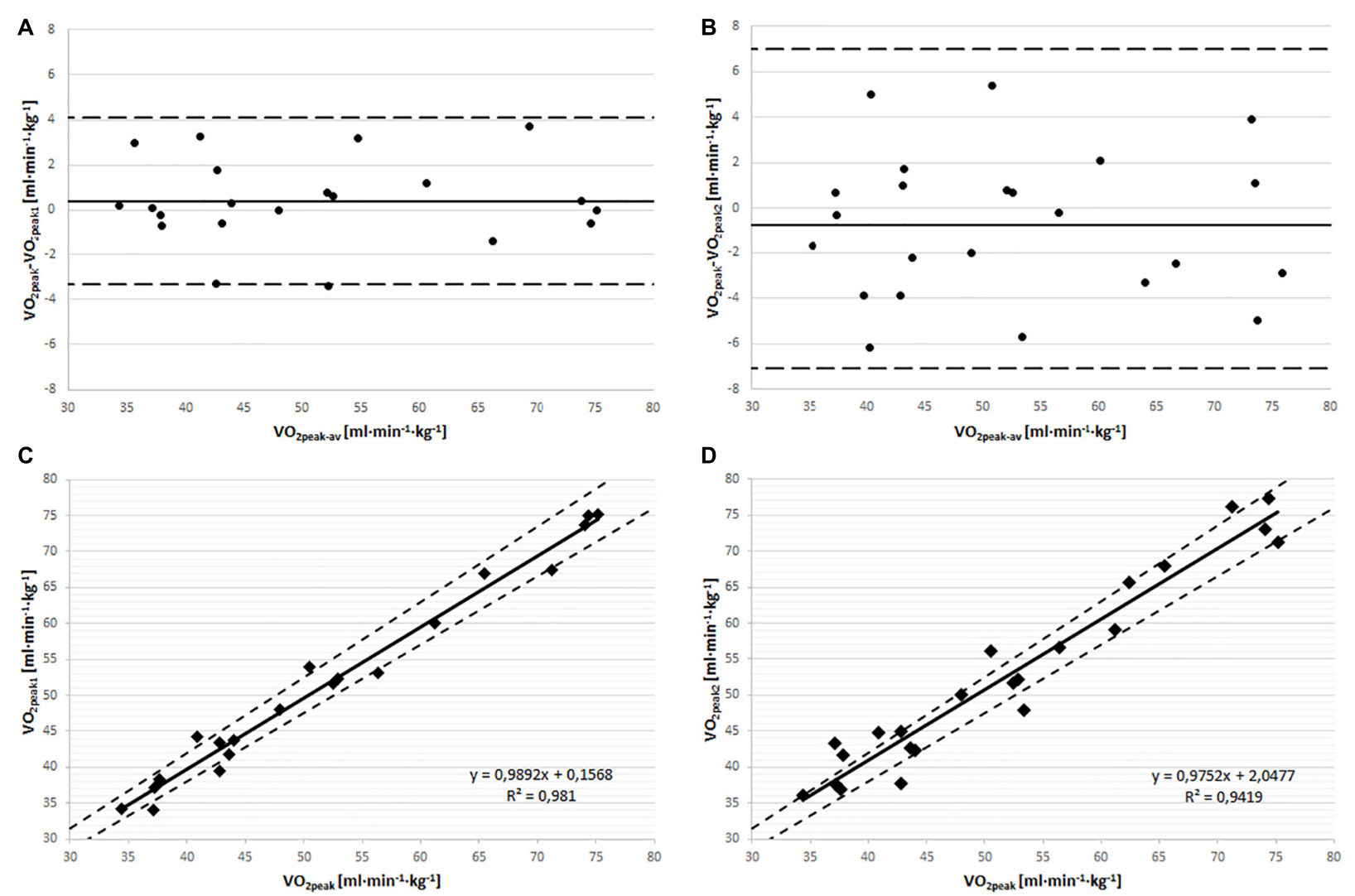

FIGURE 2 | Bland-Altman plot showing: (A) Individual differences between the $\mathrm{VO}_{2 \text { peak }}$ values attained in the incremental and $\mathrm{VO}_{2 \text { peak } 1}$ from $\mathrm{T}_{\text {ver-1 }}$ (B) individual differences between the $\mathrm{VO}_{2 \text { peak }}$ values attained in the incremental and $\mathrm{VO}_{2 \text { peak2 }}$ from $\mathrm{T}_{\text {ver-2. }}$. Solid line show bias and dashed lines represent a $1.96 \mathrm{SD}$ (standard

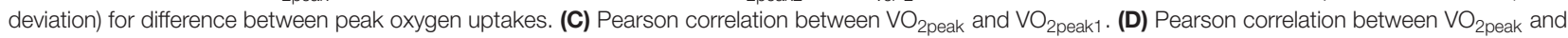
$\mathrm{VO}_{2 \text { peak2. }} \cdot \mathbf{I n}(\mathbf{C}, \mathbf{D})$ the dashed lines indicate the $5 \%$ threshold difference from $\mathrm{VO}_{2 \text { peak. }}$.

verification tests we quote above was similar. Therefore, it could be concluded that $\mathrm{VO}_{2 \text { peak }}$ in a verification test seems not to be affected by the exhaustion caused by the incremental test. Schaun (2017) also stated that the time elapsed between an incremental test and a verification test is not a key aspect to achieving the verification criterion. Attempts were also made to perform tests to verify $\mathrm{VO} 2 \mathrm{max}$ on a different day than the progressive test (Scharhag-Rosenberger et al., 2011; Possamai et al., 2020; Sawyer et al., 2020). Possamai et al. (2020) found that during the verification test performed on a separate day, the exercise capacity is greater than during the verification test performed several minutes after the progressive test. Such a conclusion was formulated on the basis of a longer effort time in a verification test performed on a separate day, compared to a test performed several minutes after the progressive test. However, the greater exercise capacity described by Possamai et al. (2020) did not affect the $\mathrm{VO}_{2 \text { peak }}$ values, which were similar in individual tests. Scharhag-Rosenberger et al. (2011) also performed verification tests on a separate day. Based on the results of these studies, it was also considered that $\mathrm{VO}_{2 \text { peak }}$ in the verification test performed on a separate day does not differ significantly from $\mathrm{VO}_{2}$ peak from the verification test performed several minutes after the progressive test. However, in the studies described above, verification tests were preceded by a short warm-up.

Another factor that may influence $\mathrm{VO}_{2}$ peak values is the type of warm-up used before the verification test carried out on a separate day. Possamai et al. (2020) preceded the verification test with a warm-up of $6 \mathrm{~min}$ and measured the power at the lactate threshold, defined as the first sharp increase in lactate concentration in a progressive test. An even shorter warm-up, lasting $5 \mathrm{~min}$, was used by Scharhag-Rosenberger et al. (2011) and Sawyer et al. (2020). In Scharhag-Rosenberger et al. (2011) study the warm-up was done at a speed higher than the lactate threshold speed. Also, a warm-up in the research of Sawyer et al. (2020) consisted of $5 \mathrm{~min}$ of exercise, however, at an intensity of $50 \mathrm{~W}$ (men) or $30 \mathrm{~W}$ (women) which is lower than those proposed by Scharhag-Rosenberger et al. (2011). Bishop (2003) stated that the optimal warm-up duration before intensive efforts with an average duration should be at least $10 \mathrm{~min}$, which allows the subject to reach steady-state $\mathrm{VO}_{2}$. In our own studies, the warm-up lasted $15 \mathrm{~min}$, including $5 \mathrm{~min}$ of VT1 effort and 10 min of effort measured halfway between VT1 and VT2. We concluded that such a warm-up, performed before the verification test on a separate day, may allow to obtain higher $\mathrm{VO}_{2 \text { peak }}$ values than in the above-cited works 
(Scharhag-Rosenberger et al., 2011; Possamai et al., 2020; Sawyer et al., 2020). This assumption was supported by the results of our own previous studies (Hebisz et al., 2017), in which we also used a long warm-up time. We then found that it is possible to achieve a higher $\mathrm{VO}_{2 \text { peak }}$ value even during a series of four short sprints (30-s each) in comparison to the progressive test. However, analysis of variance showed no statistically significant differences

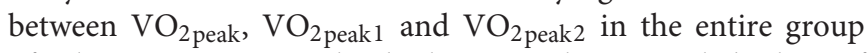
of subjects. Moreover, Bland-Altman analysis revealed a bias of $\mathrm{VO}_{2 \text { peak } 1}$ compared to $\mathrm{VO}_{2 \text { peak }}$, as well as of $\mathrm{VO}_{2 \text { peak } 2 \text { compared }}$ to $\mathrm{VO}_{2 \text { peak }}$ was neglectable. Therefore, the research procedure we used produced similar statistical effects as the research results described by Scharhag-Rosenberger et al. (2011).

The possibility that the training level meets the $\mathrm{VO}_{2 \text { peak }}$ verification criterion was also analyzed in this study. The abovecited studies (Scharhag-Rosenberger et al., 2011; Nolan et al., 2014; Possamai et al., 2020) involved physically active people, but they were not professional athletes. Only in a review, Costa et al. (2021) stated that concordance between $\mathrm{VO}_{2 \text { peak }}$ level from GXT and verification tests is not affected by the cardiorespiratory level of participants. In the present study, we compared athletes with recreationally active subjects. Analysis of variance showed no mixed effects on repeated measurements and level of physical activity. Therefore, the results of the studies described in this work support Costa et al.'s (2021) suggestion that the effects of $\mathrm{VO}_{2 \max }$ verification are not related to the level of efficiency (cardio-respiratory level).

\section{LIMITATIONS}

In our research, we compared $\mathrm{VO}_{2 \text { peak }}$ values achieved by cyclists and amateurs. In this way, our research complements the knowledge about the effects of verification tests, because so far there has been little information in the literature about the results of verification tests performed by athletes. On the other hand, performing analyses on a group of respondents consisting of cyclists and amateurs is a factor limiting the certainty of our conclusions, because athletes and amateurs are characterized by a different level of physical performance (muscular power, $\left.\mathrm{VO}_{2 \text { peak }}, \mathrm{VO}_{2 \max }\right)$. Different levels of exercise tolerance in our studies may affect the high variability of the obtained results and thus may affect the results of statistical analyses.

The second factor limiting the certainty of our conclusions is the way the subjects are prepared for the verification test performed on a separate day. After warming up, and before the verification test, we used a passive break of $15 \mathrm{~min}$. We decided that this way of preparing for the test is good, because in the literature there are suggestions that the type of break (active or passive) before a few minutes and intense efforts does not affect exercise capacity (McAinch et al., 2004; Fennell and Hopker, 2021). In addition, vasodilation of muscle vessels and the activity of histamine $\mathrm{H} 1$ and $\mathrm{H} 2$ receptors is high even for 90 min after exercise (Luttrell and Halliwill, 2017). However, the use of a passive break before the verification test performed on a separate day may have resulted in high variability of $\mathrm{VO}_{2 \text { peak }}-\mathrm{VO}_{2 \text { peak2 }}$.

\section{CONCLUSION}

Among young people, there were no statistically significant differences between $\mathrm{VO}_{2 \text { peak }}$ measured in the progressive test and $\mathrm{VO}_{2 \text { peak }}$ measured in the verification tests (performed 15 min after the progressive test and performed on a separate day), in general. There are also no differences in peak oxygen consumption between the progressive test and the verification tests after dividing the group into athletes and recreationally active individuals in any of the above-mentioned groups. In individual cases, the need to verify the maximum oxygen uptake is stated, but performing a second verification test on a separate day does not bring additional benefits.

\section{DATA AVAILABILITY STATEMENT}

The datasets presented in this study can be found in online repositories. The names of the repository/repositories and accession number(s) can be found below: https://repod.icm.edu. $\mathrm{pl} /$ dataset.xhtml?persistentId=doi:10.18150/HGE2PK.

\section{ETHICS STATEMENT}

The studies involving human participants were reviewed and approved by the Senate Research Ethics Committee at University School of Physical Education in Wrocław. The patients/participants provided their written informed consent to participate in this study.

\section{AUTHOR CONTRIBUTIONS}

$\mathrm{PH}$ contributed to the study design and data collection, and drafted the manuscript. AJ contributed to the data collection and made the critical revisions to the manuscript. $\mathrm{RH}$ contributed to the study design and data analysis, and drafted the manuscript. All authors discussed the results, commented and edited the manuscript at all stages, approved the final version and agreed to be accountable for all aspects of the work.

\section{FUNDING}

This work was supported by the University School of Physical Education in Wrocław under grant number PN/BK/2020/07. 


\section{REFERENCES}

Adam, J., Causer, A. J., Shute, J. K., Cummings, M. H., Shepherd, A. I., Bright, V., et al. (2018). Cardiopulmonary exercise testing with supramaximal verification produces a safe and valid assessment of VO2max in people with cystic fibrosis: a retrospective analysis. J. Appl. Physiol. 125, 1277-1283. doi: 10.1152/ japplphysiol.00454.2018

Astorino, T. A. (2009). Alterations in $\mathrm{VO}_{2 \max }$ and the $\mathrm{VO}_{2}$ plateau with manipulation of sampling interval. Clin. Physiol. Funct. Imaging. 29, 60-7. doi: 10.1111/j.1475-097X.2008.00835.x

Astorino, T. A., and DeRevere, J. (2018). Efficacy of constant load verification testing to confirm $\mathrm{VO}_{2} \max$ attainment. Clin. Physiol. Funct. Imaging 38, 703-709. doi: 10.1111/cpf.12474

Barker, A. R., Williams, C. A., Jones, A. M., and Armstrong, N. (2011). Establishing maximal oxygen uptake in young people during a ramp cycle test to exhaustion. Br. J. Sports Med. 45, 498-503. doi: 10.1136/bjsm.2009.063180

Bassett, D. R., and Howley, E. T. (2000). Limiting factors for maximum oxygen uptake and determinants of endurance performance. Med. Sci. Sports Exerc. 32, 70-84.

Beaver, W. L., Wasserman, K., and Whipp, B. J. (1986). A new method for detecting anaerobic threshold by gas exchange. J. Appl. Physiol. 60, 2020-2027. doi: 10. 1152/jappl.1986.60.6.2020

Beltz, N. M., Gibson, A. L., Janot, J. M., Kravitz, L., Mermier, C. M., and Dalleck, L. C. (2016). Graded exercise testing protocols for the determination of $\mathrm{VO}_{2}$ max: historical perspectives, progress, and future considerations. J. Sports Med. 2016:3968393. doi: 10.1155/2016/3968393

Bishop, D. (2003). Warm up II: performance changes following active warm up and how to structure the warm up. Sports Med. 33, 483-498. doi: 10.2165/00007256200333070-00002

Brito, J., Fernandes, L., Rebelo, A., Krustrup, P., Silva, G., and Oliveira, J. (2019). Heart rate kinetics response of pre-pubertal children during the YoYo intermittent endurance test-level 1. Sports 7:65. doi: 10.3390/sports70 30065

Costa, V. A. B., Midgley, A. W., Carroll, S., Astorino, T. A., de Paula, T., Farinatti, P., et al. (2021). Is a verification phase useful for confirming maximal oxygen uptake in apparently healthy adults? A systematic review and meta-analysis. PLoS One 16:e0247057. doi: 10.1371/journal.pone.0247057

Dalleck, L. C., Astorino, T. A., Erickson, R. M., McCarthy, C. M., Beadell, A. A., and Botten, B. H. (2012). Suitability of verification testing to confirm attainment of VO2max in middle-aged and older adults. Res. Sports Med. 20, 118-128. doi: 10.1080/15438627.2012.660825

Davis, J. A., Whipp, B. J., and Wasserman, K. (1980). The relation of ventilation to metabolic rate during moderate exercise in man. Eur. J. Appl. Physiol. Occup. Physiol. 44, 97-108. doi: 10.1007/BF00421087

Duncan, G. E., Howley, E. T., and Johnson, B. N. (1997). Applicability of VO2max criteria: discontinuous versus continuous protocols. Med. Sci. Sports Exerc. 29, 273-278. doi: 10.1097/00005768-199702000-00017

Fennell, C. R. J., and Hopker, J. G. (2021). The acute physiological and perceptual effects of recovery interval intensity during cycling-based high-intensity interval training. Eur. J. Appl. Physiol. 121, 425-434. doi: 10.1007/s00421-02004535-x

Hall-Lopez, J. A., Ochoa-Martinez, P. Y., Moncada-Jimenez, J., Mendez, M. A. O., Garcia, I. M., and Garcia, M. A. M. (2015). Reliability of the maximal oxygen uptake following two consecutive trials by indirect calorimetry. Nutr. Hosp. 31, 1726-1732. doi: 10.3305/nh.2015.31.4.8487

Hebisz, P., Hebisz, R., Borkowski, J., and Zatoń, M. (2018). Time of $\mathrm{VO}_{2} \max$ plateau and postexercise oxygen consumption during incremental exercise testing in young mountain bike and road cyclists. Physiol. Res. 67, 711-719.

Hebisz, R., Hebisz, P., Zatoń, M., and Michalik, K. (2017). Peak oxygen uptake in a sprint interval testing protocol vs. maximal oxygen uptake in an incremental testing protocol and their relationship with cross-country mountain biking performance. Appl. Physiol. Nutr. Metab. 42, 371-376. doi: 10.1139/apnm2016-0362

Howley, E. T., Bassett, D. R., and Welch, H. G. (1995). Criteria for maximal oxygen uptake: review and commentary. Med. Sci. Sports Exerc. 27, 1292-1301.

Joyner, M. J., and Coyle, E. F. (2008). Endurance exercise performance: the physiology of champions. J. Physiol. 586, 35-44.
Kirkeberg, J. M., Dalleck, L. C., Kamphoff, C. S., and Pettitt, R. W. (2011). Validity of 3 protocols for verifying VO2max. Int. J. Sports Med. 32, 266-270. doi: 10.1055/s-0030-1269914

Lucia, A., Hoyos, J., and Chicharro, J. L. (2001). Physiology of professional road cycling. Sports Med. 31, 325-337.

Lucia, A., Rabadan, M., Hoyos, J., Hernandez-Capilla, M., Perez, M., San Juan, A. F., et al. (2006). Frequency of the VO2max plateau phenomenon in worldclass cyclists. Int. J. Sports Med. 27, 984-992. doi: 10.1055/s-2006-923833

Luttrell, M. J., and Halliwill, J. R. (2017). The intriguing role of histamine in exercise responses. Exerc. Sport. Sci. Rev. 45, 16-23. doi: 10.1249/JES.0000000000000093

Martino, M., Gledhill, N., and Jamnik, V. (2002). High VO2max with no history of training is primarily due to high blood volume. Med. Sci. Sports Exerc. 34, 966-971.

McAinch, A. J., Febbraio, M. A., Parkin, J. M., Zhao, S., Tangalakis, K., Stojanovska, L., et al. (2004). Effect of active versus passive recovery on metabolism and performance during subsequent exercise. Int. J. Sport Nutr. Exerc. Metab. 14, 185-196. doi: 10.1123/ijsnem.14.2.185

McGawley, K. (2017). The reliability and validity of a four-minute running timetrial in assessing $\mathrm{VO}_{2}$ max and performance. Front. Physiol. 8:270. doi: 10.3389/ fphys.2017.00270

Midgley, A. W., McNaughton, L. R., and Carroll, S. (2006). Verification phase as a useful tool in the determination of the maximal oxygen uptake of distance runners. Appl. Physiol. Nutr. Metab. 31, 541-548.

Midgley, A. W., McNaughton, L. R., and Carroll, S. (2007a). Effect of VO2 timeaveraging interval on reproducibility of $\mathrm{VO} 2 \mathrm{max}$ in healthy athletic subjects. Clin. Physiol. Funct. Imaging 27, 122-125. doi: 10.1111/j.1475-097X.2007. 00725.x

Midgley, A. W., McNaughton, L. R., Polman, R., and Marchant, D. (2007b). Criteria for determination of maximal oxygen uptake: a brief critique and recommendations for future research. Sports Med. 37, 1019-1028. doi: 10.2165/ 00007256-200737120-00002

Murias, J. M., Pogliaghi, S., and Paterson, D. H. (2018). Measurement of a true VO2max during a ramp incremental test is not confirmed by a verification phase. Front. Physiol. 9:143. doi: 10.3389/fphys.2018.00143

Niemelä, K., Palatsi, I., Linnaluoto, M., and Takkunen, J. (1980). Criteria for maximum oxygen uptake in progressive bicycle tests. Eur. J. Appl. Physiol. Occup. Physiol. 44, 51-59. doi: 10.1007/BF00421763

Nolan, P. B., Beaven, M. L., and Dalleck, L. (2014). Comparison of intensities and rest periods for VO2max verification testing procedures. Int. J. Sports Med. 35, 1024-1029. doi: 10.1055/s-0034-1367065

Poole, D. C., and Jones, A. M. (2017). Measurement of the maximum oxygen uptake $\dot{\mathrm{VO}}_{2}$ max: $\dot{\mathrm{VO}}_{2}$ peak is no longer acceptable. J. Appl. Physiol. 122, $997-$ 1002. doi: 10.1152/japplphysiol.01063.2016

Poole, D. C., Wilkerson, D. P., and Jones, A. M. (2008). Validity of criteria for establishing maximal $\mathrm{O}_{2}$ uptake during ramp exercise test. Eur. J. Appl. Physiol. 102, 403-410. doi: 10.1007/s00421-007-0596-3

Possamai, L. T., Campos, F. S., Salvador, P. C., de Aguiar, R. A., Guglielmo, L. G., de Lucas, R. D., et al. (2020). Similar maximal oxygen uptake assessment from a step cycling incremental test and verification tests on the same or different day. Appl. Physiol. Nutr. Metab. 45, 357-361. doi: 10.1139/apnm-2019-0405

Romero-Fallas, O., Soto-Arias, M., and Moncada-Jimenze, J. (2012). Maximal oxygen consumption in college students is reliable following four consecutive trials. J. Phys. Edu. Sport 12, 476-481. doi: 10.7522/jpes.2012.04069

Rossiter, H. B., Kowalchuk, J. M., and Whipp, B. J. (2006). A test to establish maximum $\mathrm{O} 2$ uptake despite no plateau in the $\mathrm{O} 2$ uptake response to ramp incremental exercise. J. Appl. Physiol. 100, 764-770. doi: 10.1152/japplphysiol. 00932.2005

Sánchez-Otero, T., Iglesias-Soler, E., Boullosa, D. A., and Tuimil, J. L. (2014). Verification criteria for the determination of $\mathrm{VO}_{2} \max$ in the field. J. Strength Cond. Res. 28:35443551. doi: 10.1519/JSC.0000000000000576

Sawyer, B. J., McMahon, N., Thornhill, K. L., Baughman, B. R., Mahoney, J. M., Pattison, K. L., et al. (2020). Supra-versus submaximal cycle ergometer verification of $\mathrm{VO}_{2 \max }$ in males and females. Sports 8:163. doi: 10.3390/ sports8120163

Scharhag-Rosenberger, F., Carlsohn, A., Cassel, M., Mayer, F., and Scharhag, J. (2011). How to test maximal oxygen uptake: a study on timing and testing procedure of a supramaximal verification test. Appl. Physiol. Nutr. Metab. 36, 153-160. doi: 10.1139/H10-099 
Schaun, G. Z. (2017). The maximal oxygen uptake verification phase: a light at the end of the tunnel? Sports Med. Open 3:44. doi: 10.1186/s40798-017-0112-1

Conflict of Interest: The authors declare that the research was conducted in the absence of any commercial or financial relationships that could be construed as a potential conflict of interest.

Publisher's Note: All claims expressed in this article are solely those of the authors and do not necessarily represent those of their affiliated organizations, or those of the publisher, the editors and the reviewers. Any product that may be evaluated in this article, or claim that may be made by its manufacturer, is not guaranteed or endorsed by the publisher.

Copyright (c) 2021 Hebisz, Jastrzębska and Hebisz. This is an open-access article distributed under the terms of the Creative Commons Attribution License (CC BY). The use, distribution or reproduction in other forums is permitted, provided the original author(s) and the copyright owner(s) are credited and that the original publication in this journal is cited, in accordance with accepted academic practice. No use, distribution or reproduction is permitted which does not comply with these terms. 